\title{
Correction to: A Survey of Residents/Fellows, Program Directors, and Faculty About Telepsychiatry: Clinical Experience, Interest, and Views/Concerns
}

\author{
Cesar Cruz $^{1} \cdot$ Kali Orchard $^{2}$ - Erica Z. Shoemaker ${ }^{3} \cdot$ Donald M. Hilty $^{4,5}$ \\ Published online: 4 March 2021 \\ (c) Springer Nature Switzerland AG 2021
}

\section{Correction to: Journal of Technology in Behavioral Science https://doi.org/10.1007/s41347-020-00164-5}

The article A Survey of Residents/Fellows, Program Directors, and Faculty About Telepsychiatry: Clinical Experience, Interest, and Views/Concerns, written by Cesar Cruz, Kali Orchard, Erica Z. Shoemaker and Donald M. Hiltyr, was originally published electronically on the publisher's internet portal (currently SpringerLink) on 09 February 2021 with open access. With the author(s)' decision to step back from Open Choice, the copyright of the article changed on March 2021 to () The Author(s), under exclusive licence to Springer Nature Switzerland AG part of Springer Nature 2021.

The original article can be found online at https://doi.org/10.1007/ s41347-020-00164-5

Donald M. Hilty

donh032612@gmail.com

Cesar Cruz

cesarcruzmd10@gmail.com

Kali Orchard

kali_orchard@hotmail.com

Erica Z. Shoemaker

ezshoema@med.usc.edu

1 Child and Adolescent Psychiatry, USC Institute of Psychiatry \& Law, Los Angeles, CA, USA

2 Yellowknife Adult and Child Psychiatry, Yellowknife, Canada

3 Department of Psychiatry \& Behavioral Sciences, Keck School of Medicine, USC and LAC+USC Medical Center, Los Angeles, CA, USA

4 Northern California Veterans Administration Health Care System, 10535 Hospital Way, Mather, CA 95655 (116/SAC), USA

5 Department of Psychiatry \& Behavioral Sciences, UC Davis, Davis, CA, USA
The original article has been corrected.

Publisher's Note Springer Nature remains neutral with regard to jurisdictional claims in published maps and institutional affiliations. 